\title{
Distribution of yttrium 90 ferric hydroxide colloid and gold 198 colloid after injection into knee
}

\author{
E. D. Williams, D. E. CAUGHEY, P. J. HURLEY, AND M. B. JOHN \\ From the Departments of Nuclear Medicine and Rheumatology, Auckland Hospital, \\ Auckland, New Zealand
}

\begin{abstract}
Williams, E. D., Caughey, D. E., Hurley, P. J., and John, M. B. (1976). Annals of the Rheumatic Diseases, 35, 516-520. Distribution of yttrium 90 ferric hydroxide colloid and gold 198 colloid after injection into knee. Thirteen knees were injected with yttrium $90\left({ }^{90} \mathrm{Y}\right)$ ferric hydroxide colloid, and 12 with gold $198\left({ }^{198} \mathrm{Au}\right)$ colloid for treatment of persistent synovitis. Retention in the knee and uptake in lymph nodes and liver were measured by a quantitative scanning technique. There was no significant difference in the retention in the knee of the two different colloids. A tendency towards higher lymph node uptake was observed with ${ }^{198} \mathrm{Au}$ compared with ${ }^{90} \mathrm{Y}$. The inflammatory activity of the knee at the time of treatment may have influenced the subsequent lymph node uptake of ${ }^{198} \mathrm{Au}$, but not that of the ${ }^{90} \mathrm{Y}$, nor the overall leakage of either from the knee. ${ }^{90} \mathrm{Y}$ ferric hydroxide colloid was retained in the treated knee at least as well as other colloids which have been used for this purpose.
\end{abstract}

After intra-articular injection of radioactive colloids for treatment of persistent synovitis of the knee (Ansell and others 1963), radioactivity escapes from the knee and has been observed in the regional lymph nodes and liver (Ahlberg, Mikulowski, and Odelberg-Johnson, 1969; Grahame, Ramsey, and Scott, 1970; Topp and Cross, 1970; Riccabona and Junger, 1970; Prichard, Bridgman, and Bleehen, 1970; Fearn, 1973; Ramsey, 1973). High radiation doses to the lymph nodes can result (Virkkunen, Krusius, and Heiskanen, 1967; Stevenson and others, 1973), so it is useful to investigate means of reducing this unwanted radiation hazard. Resting the joint has been shown to reduce leakage (Oka and others, 1971; Gumpel, Williams, and Glass, 1973). Ingrand (1973) suggested that larger colloidal particles leak less than smaller particles. It is difficult to compare the reported behaviour of different radioactive colloids in order to verify such a hypothesis, because in the various studies the methods of measurement of radioactivity have been different, and the amount of exercise of the treated joint during the period of study has not been constant.

Our patients were treated with two radioactive colloids, gold $198\left({ }^{198} \mathrm{Au}\right)$ and yttrium $90\left({ }^{90} \mathrm{Y}\right)$, which have different ranges of particle sizes, and the resulting distributions of radioactivity in the body were compared. Patients were prevented from exercising the treated joint for 4 days after injection. A similar method of measurement of radioactivity was used with both radionuclides. The ${ }^{90} \mathrm{Y}$ colloid used was a newly available preparation, ${ }^{90} \mathrm{Y}$ ferric hydroxide. Data on its distribution were compared with those from published studies in which other yttrium colloids were used. Since the degree of inflammation in the joint before treatment may also be relevant to the behaviour of colloids (Goode and Howey, 1973), an attempt was made to quantify this inflammation in each patient.

\section{Materials and methods}

${ }^{198} \mathrm{Au}$ colloid (code no. GCS. 1P) and ${ }^{90} \mathrm{Y}$ ferric hydroxide colloid (code no. YA. X939) were obtained from the Or Radiochemical Centre, Amersham, England. The particle N size of ${ }^{198} \mathrm{Au}$ colloid is stated to be of the order of $10 \mathrm{~nm}$. N Measurements from electron micrographs of the ${ }^{90} \mathrm{Y}{ }^{\mathrm{W}}$ colloid showed its mean particle size to be about $5 \mu \mathrm{m}$. The radioactivity injected into the knee joint, $10 \mathrm{mCi}$ for $\Theta$ ${ }^{198} \mathrm{Au}$, and $5 \mathrm{mCi}$ for ${ }^{20} \mathrm{Y}$, was contained in a volume of $2-3 \mathrm{ml}$ and injected through a $20 \mathrm{G}$ needle.

Radioactivity retained in the knee and that taken up 0 by the inguinal and neighbouring lymph nodes and by 
the liver was measured by a quantitative scanning technique (Williams, 1973a) using a dual $5^{\prime \prime}(12 \cdot 7 \mathrm{~cm})$ detector Picker scanner with high energy focused collimators (type $2111,5^{\prime \prime}$ focal length, $0 \cdot 5^{\prime \prime}$ resolution). For measurements of gamma radiation from ${ }^{198} \mathrm{Au}$ in the knee, a $6 \mathrm{~mm}$-thick lead plate was placed in front of each collimator to reduce the count rate sufficiently to allow accurate measurement. With ${ }^{90} \mathrm{Y}$, the bremsstrahlung was of much lower intensity so the lead plate was not needed. Instead, a $1 \mathrm{~mm}$ thick aluminium plate was used to absorb any beta radiation which may have penetrated the skin from radioactivity close to the surface. A different set of high energy collimators ( $3^{\prime \prime}$ focal length, $1^{\prime \prime}$ resolution) with high efficiency were used when scanning the lymph nodes and liver for ${ }^{90} \mathrm{Y}$, because the radiation intensity from these sites was low.

The knee was scanned within 30 minutes of injection with the patient supine. The knee, lymph nodes, and liver were also scanned 2, 4, and 7 days later. Radioactivity at each site was quantified by counting the numbers of dots in the appropriate region on dot scans, after subtraction of a 'background' level estimated from another part of the scan. For the knee, subsequent measurements of retention of radioactivity were expressed as a percentage of the initial value. For the lymph nodes and liver, calibration factors relating counts obtained by scanning to the quantity of radioactivity present were obtained by scanning a radioactive source placed in a water tank.

Corrections for attenuation by overlying tissue were calculated according to the measured thickness of the appropriate part of the patient's body. By scanning a radioactive source in a water tank it was found that to obtain results approximately independent of the depth of ${ }^{198} \mathrm{Au}$ radioactivity within the body, the geometric mean of the net number of counts from the detectors above and below the patient should be calculated. For ${ }^{90} \mathrm{Y}$, however, the arithmetic mean was found to give better depth-independence. In some cases when the uptake of ${ }^{90} \mathrm{Y}$ in lymph nodes was low, attenuation of radiation by body tissues was such that no increase in count rate was detectable with the lower detector despite an increased count rate from the upper detector. Data from the upper detector only were then used in calculating the uptake, with the assumption that the radioactivity lay at a depth of $4 \mathrm{~cm}$. If the lymph nodes lay within $\pm 2 \mathrm{~cm}$ of this depth, the error introduced by this assumption was no more than $\pm 20 \%$.

A comparison of scans of water phantoms and measurements of the transmission of ${ }^{90} \mathrm{Y}$ and ${ }^{198} \mathrm{Au}$ radiations through knees showed that the method used for correction for attenuation by body tissues contributed to a relative error in the result of no more than $\pm 2 \%$ for either radionuclide. The total estimated relative error (95\% confidence limits) in the measurement of retention in the knee was $\pm 8 \%$ (Williams, 1973b) and in the liver and lymph nodes, $\pm 11 \%$. There was a larger error in measurements of ${ }^{90} \mathbf{Y}$ in the lymph nodes and liver when the uptake at these sites was very low $(<1 \%$ of injected radioactivity) owing to the increased contribution of the statistical error of counting and in some cases, the use of an estimated lymph node depth. The relative error in these measurements was then about $\pm 20-30 \%$.
Radioactivity in venous blood samples taken at the times when the patients were scanned, and in 24-hour urine collections made over the first few days after injection, was measured using a well scintillation counter and compared with that in an aliquot of the injected radioactivity. Radioactivity in the blood of the whole body was deduced with the aid of blood volume tables (Hurley, 1975).

Inflammation in the knee was estimated 5 days before treatment by measuring the uptake of ${ }^{99} \mathrm{Tcm}$-pertechnetate by a method similar to that of Karjalainen, Kettunen, and Holopainen (1972). The rectilinear scanner was used to scan the knees 30 minutes after an intravenous injection of $5 \mathrm{mCi}{ }^{99} \mathrm{Tc}^{\mathrm{m}}$-pertechnetate. The number of dots in each scan line (made at right angles to the long axis of the leg) was counted and a count-rate profile of the knee was constructed. Uptake in the knee ('inflammation index') was expressed as the ratio of the maximum count rate over the knee to that over the calf $18 \mathrm{~cm}$ below the superior edge of the patella. In healthy subjects, the value of this ratio is stated to be $0 \cdot 9-1 \cdot 4$. Values between 1.5 and 3.5 have been obtained in inflamed knees (Karjalainen and others, 1972).

Nineteen patients were treated; 13 knees were treated with ${ }^{90} \mathrm{Y}$ and 12 with ${ }^{198} \mathrm{Au}$ ( 6 patients had both knees treated, one with ${ }^{90} \mathrm{Y}$ and the other with $\left.{ }^{198} \mathrm{Au}\right)$. All patients had persistent synovitis of the knee associated with rheumatoid arthritis or with osteoarthrosis. Patients were treated in groups of 3,4 , or 5 at a time. They were not preselected for treatment with a particular radionuclide: alternate groups were treated with each radionuclide in turn. After the knee was injected, it was immobilized with a metal splint at the back of the knee, and the patient was rested in bed for 4 days.

\section{Results}

For 3 of the patients treated with ${ }^{90} \mathrm{Y}$, measurements were obtained after 1 and 3 days, rather than 2 and 4: data for the latter times were then obtained by linear interpolation and extrapolation. Radioactivity retained in the knees is shown in Table $I$. There was no significant difference $(P>0.7)$ between the retention in the knee of ${ }^{198} \mathrm{Au}$ and ${ }^{90} \mathrm{Y}$ at any time during the period of study.

Table I Radioactivity retained in the knee (as a percentage of radioactivity present shortly after injection; corrected for decay)

\begin{tabular}{|c|c|c|c|c|c|c|}
\hline \multirow[t]{2}{*}{ Radionuclide } & \multicolumn{2}{|l|}{ Day 2} & \multicolumn{2}{|l|}{ Day 4} & \multicolumn{2}{|l|}{ Day 7} \\
\hline & Mean & $S D$ & Mean & $S D$ & Mean & $S D$ \\
\hline $\begin{array}{c}{ }^{90} \mathrm{Y} \\
{ }^{198} \mathrm{Au}\end{array}$ & $\begin{array}{l}94 \\
96\end{array}$ & $\begin{array}{l}6 \\
8\end{array}$ & $\begin{array}{l}90 \\
92\end{array}$ & $\begin{array}{r}9 \\
10\end{array}$ & $\begin{array}{l}82 \\
88\end{array}$ & $\begin{array}{l}13 \\
13\end{array}$ \\
\hline
\end{tabular}

Uptake in the lymph nodes (the sum of uptake in femoral, inguinal, and para-aortic groups of nodes) and in the liver are shown in Tables II and III, respectively. The mean uptake of ${ }^{198} \mathrm{Au}$ was higher than that of ${ }^{90} \mathrm{Y}$ at both sites, but the difference 
between the uptake of the two radionuclides in the liver $(P>0.7)$ and in the lymph nodes $(P>0.15)$ was not significant. The nonparametric randomization test was used for these comparisons since the data for ${ }^{198} \mathrm{Au}$ were not normally distributed.

Very small amounts of radioactivity were found in blood and urine. The amounts in the 24-hour urine collections from different patients correlated with the amounts in their blood $(P<0.02)$. The mean amounts in the whole blood volume of the patients were similar for the two radionuclides $\left(0.13 \%\right.$ of the injected dose for ${ }^{90} \mathrm{Y}$ and $0.19 \%$ for $\left.{ }^{198} \mathrm{Au}\right)$, but there was more ${ }^{90} \mathrm{Y}(0.19 \%)$ in the 24-hour urine collections than ${ }^{198} \mathrm{Au}(0.01 \%)$. The ${ }^{90} \mathrm{Y}$ levels are similar to those found by Prichard and others (1970) in patients injected with ${ }^{90} \mathrm{Y}$ resin colloid.

The mean inflammation index of the knee before treatment was similar in the two groups of knees: 2.12 in those treated with ${ }^{198} \mathrm{Au}$ and 2.06 in those treated with ${ }^{90} \mathrm{Y}$. The retention of radioactivity in the knee was not found to be related to the inflammation index before treatment for either radionuclide. The relations between all the quantities

Table II Radioactivity in lymph nodes (as a percentage of radioactivity injected; corrected for decay)

\begin{tabular}{|c|c|c|c|}
\hline Case no. & Day 2 & Day 4 & Day 7 \\
\hline \multicolumn{4}{|l|}{ (a) ${ }^{90} \mathrm{Y}$} \\
\hline 1 & $\begin{array}{l}3 \cdot 1 \\
1 \cdot 9\end{array}$ & $\begin{array}{l}3.2 \\
2.9\end{array}$ & $\begin{array}{l}4.0 \\
2.6\end{array}$ \\
\hline $\begin{array}{l}2 \\
3\end{array}$ & $0 \cdot 37$ & $1 \cdot 2$ & 1.3 \\
\hline 4 & 0 & 0 & 0 \\
\hline 5 & 0 & 0 & 0 \\
\hline 6 & 0 & 0 & 0 \\
\hline 7 & $0 \cdot 51$ & $0 \cdot 71$ & $1 \cdot 1$ \\
\hline 8 & 0.61 & $2 \cdot 9$ & $2 \cdot 2$ \\
\hline 9 & 0 & 0 & 0 \\
\hline 10 & $1 \cdot 0$ & $1 \cdot 8$ & $2 \cdot 8$ \\
\hline 11 & $0.22 *(0.53)$ & $0.83+(0.82)$ & 0.80 \\
\hline 12 & $0 \cdot 28 *(0 \cdot 79)$ & $1 \cdot 3 \dagger \quad(2 \cdot 1)$ & $4 \cdot 7$ \\
\hline 13 & $0 \cdot 26 *(0 \cdot 28)$ & $0 \cdot 30 \dagger(0 \cdot 30)$ & $0 \cdot 30$ \\
\hline Mean & 0.69 & $1 \cdot 4$ & $1 \cdot 5$ \\
\hline \multicolumn{4}{|l|}{ (b) ${ }^{198} \mathrm{Au}$} \\
\hline 1 & 0.41 & $0 \cdot 52$ & $1 \cdot 0$ \\
\hline 4 & 0.04 & $0 \cdot 19$ & $0 \cdot 15$ \\
\hline $\begin{array}{l}5 \\
6\end{array}$ & $\begin{array}{c}0 \\
6 \cdot 3\end{array}$ & $\begin{array}{c}0 \\
7 \cdot 6\end{array}$ & $\begin{array}{c}0 \\
8 \cdot 5\end{array}$ \\
\hline 8 & 0.25 & 0.36 & $1 \cdot 3$ \\
\hline 10 & $5 \cdot 9$ & $6 \cdot 3$ & $6 \cdot 6$ \\
\hline 14 & 0.01 & 0 & 0 \\
\hline 15 & $6 \cdot 2$ & $7 \cdot 5$ & $8 \cdot 3$ \\
\hline 16 & $0 \cdot 37$ & $0 \cdot 33$ & $0 \cdot 48$ \\
\hline 17 & $9 \cdot 4$ & $9 \cdot 8$ & $11 \cdot 1$ \\
\hline $\begin{array}{l}18 \\
19\end{array}$ & $\begin{array}{c}0 \\
15 \cdot 5\end{array}$ & $\begin{array}{l}0 \\
14.0\end{array}$ & $\begin{array}{c}0 \\
14 \cdot 2\end{array}$ \\
\hline & & & 4 . \\
\hline
\end{tabular}

* Day 1; † day 3

Values in parentheses are those interpolated for day 2 and day 4. measured were investigated. The uptake of ${ }^{198} \mathrm{Au}$ in the lymph nodes may have been related to the inflammation index of the treated joint (Fig. 1) although this relationship was significant at the $10 \%$

Table III Radioactivity in liver (as a percentage ofo radioactivity injected; corrected for decay)

\begin{tabular}{|c|c|c|}
\hline Case no. & Day 2 & Day 4 \\
\hline \multicolumn{3}{|l|}{ (a) ${ }^{90} \mathrm{Y}$} \\
\hline 1 & - & $2 \cdot 2$ \\
\hline 2 & $\overline{-}$ & 0 \\
\hline 3 & $\mathbf{0}$ & $0 \cdot 37$ \\
\hline 4 & $\overline{0}$ & $\overline{0}$ \\
\hline 5 & 0 & 0 \\
\hline 6 & 0 & 0 \\
\hline 7 & 0 & 0 \\
\hline 8 & $0 \cdot 88$ & $3 \cdot 4$ \\
\hline 9 & 0 & 0 \\
\hline 10 & $0 \cdot 38$ & $1 \cdot 2$ \\
\hline 11 & $0 \cdot 18^{*}(0 \cdot 51)$ & $0.83 \dagger(1 \cdot 2)$ \\
\hline 12 & $1 \cdot 12 *(0.99)$ & $1.9 \dagger \quad(2.0)$ \\
\hline \multirow{2}{*}{$\overline{\text { Mean }}$} & & \\
\hline & $0 \cdot 28$ & $0 \cdot 86$ \\
\hline \multicolumn{3}{|l|}{ (b) ${ }^{198} \mathrm{Au}$} \\
\hline 1 & $0 \cdot 35$ & 0.24 \\
\hline 4 & 0 & 0 \\
\hline 5 & 0 & 0 \\
\hline $\begin{array}{l}6 \\
8\end{array}$ & $1 \cdot 8$ & $1 \cdot 4$ \\
\hline $\begin{array}{r}8 \\
10\end{array}$ & $\begin{array}{l}0.06 \\
0.20\end{array}$ & $\begin{array}{l}0.06 \\
0.28\end{array}$ \\
\hline $\begin{array}{l}10 \\
14\end{array}$ & $\begin{array}{l}0.20 \\
-\end{array}$ & 0.15 \\
\hline 15 & 0.61 & 0.73 \\
\hline 16 & 0.06 & 0.05 \\
\hline 17 & $7 \cdot 4$ & $8 \cdot 0$ \\
\hline $\begin{array}{l}18 \\
19\end{array}$ & $0 \cdot 18$ & $0 \cdot 18$ \\
\hline 19 & $2 \cdot 5$ & $2 \cdot 4$ \\
\hline
\end{tabular}

Day 7

$2 \cdot 4$

-

-

-

-

$2 \cdot 0$ w

-

0 ir

$2 \cdot 3$

$0 \stackrel{1}{2}$

$1 \cdot 5$

$0 \cdot 22$

0

$1 \cdot 6$ 응 $0 \cdot 15$.

$0 \cdot 41$ 을 응

0.51.

0.05

$8 \cdot 0$

$0 \cdot 17$

$2 \cdot 5$

$2 \cdot 5$

* Day $1 ; \dagger$ day $3 ;-=$ not scanned.

Values in parentheses are those interpolated for day 2 and day 4.

level only, and there was no suggestion of such $\mathrm{a}$. relation for ${ }^{90} \mathrm{Y}$ (Fig. 2), and none of the other measurements were found to be significantly. related to the inflammation index. Radioactivity in the urine, blood, liver, and lymph nodes, and radioactivity lost from the knee, were in most cases inter-related. These relationships were generally? closer, having higher correlation coefficients for ${ }^{198} \mathrm{Au}$ than for ${ }^{90} \mathrm{Y}$.

\section{Discussion}

What affects retention of colloids in the knee, apart $\bar{O}$ from the amount of exercise of the joint, remains unclear. We found no significant difference in the retention of two colloids of widely differing particle $\stackrel{\infty}{+}$ size nor any correlation between retention and joint 7 inflammation before treatment. Chemical stability of the colloid may be important, as has been suggested by Gumpel, Farran, and Williams (1974), but 


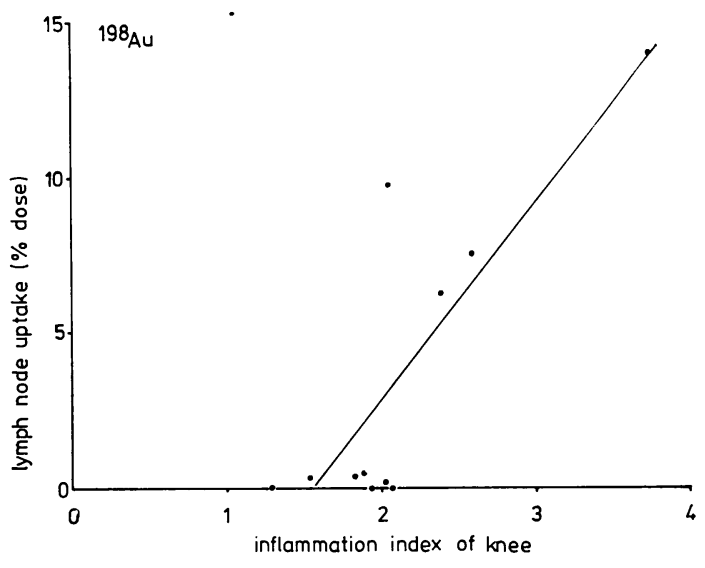

FIG. 1 Uptake of ${ }^{198} \mathrm{Au}$ colloid in lymph nodes 4 days after injection into the knee suggests a correlation with the degree of inflammation of the knee. The line of linear regression is shown $(r=0.83 ; 0.05<\mathrm{P}<0.1)$

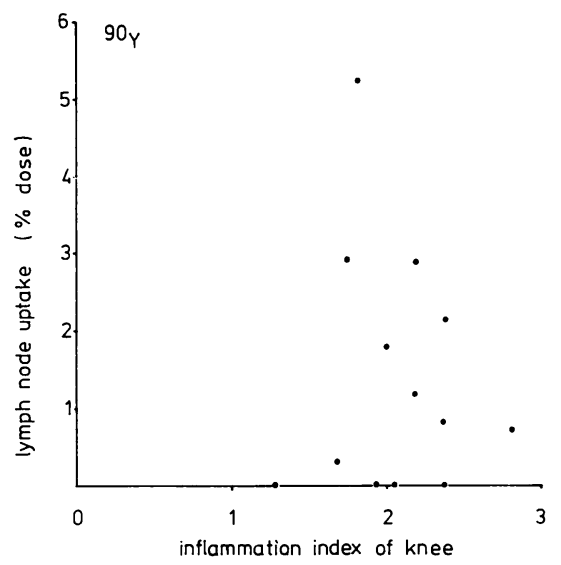

FIG. 2 Uptake of ${ }^{90} Y$ ferric hydroxide colloid in lymph nodes 4 days after injection into the knee is unrelated to the degree of inflammation of the knee

variations in the extent to which the treated limb is rested in different series prevent comparisons of published data in this respect. In addition, the variation in knee retention between different patients is sufficiently large that any small differences in behaviour of the radiopharmaceutical are unlikely to be easily detected. Thus, in a comparison of the behaviour of four different ${ }^{90} \mathrm{Y}$ colloids, Gumpel and Stevenson (1975) did not find any statistically significant difference among them.

Goode and Howey (1973) have suggested that leakage of ${ }^{198} \mathrm{Au}$ may occur more frequently from those knees exhibiting greater inflammatory activity at the time of injection. Our observations of lymph node uptake provide slight and barely significant support for this hypothesis. However, our failure to find a relation between inflammation of the knee and loss of radioactivity from it suggests that in the patients we have studied inflammation of the knee did not have a major influence on the retention of radioactivity within it.

Particle size may, however, affect the subsequent uptake in lymph nodes and liver. In our series the uptake of ${ }^{198} \mathrm{Au}$ in lymph nodes seemed to fall into two groups, either high ( $>6 \%$ of the injected dose) or low $(<1 \%)$, while results for ${ }^{90} \mathrm{Y}$ were more evenly spread and were on average lower. This difference in behaviour may be connected with the relation between lymph node uptake and knee joint inflammation observed for ${ }^{198} \mathrm{Au}$ only. The ratio of the mean uptake in lymph nodes to that in liver was higher $(3 \cdot 1,3 \cdot 3$, and $3 \cdot 6$ on days 2 , 4 , and 7 respectively) for ${ }^{198} \mathrm{Au}$ than for ${ }^{90} \mathrm{Y}(2 \cdot 5,1 \cdot 6$, and 1.0). Caro, Nicolini, and Radicella (1968) also found relatively greater lymph node uptake compared to liver uptake in mice, for smaller as compared to larger sized ${ }^{198} \mathrm{Au}$ colloids. Thus, while colloidal particle size may have little effect on the proportion retained in the knee, it may have a greater influence on the subsequent uptake in regional lymph nodes, thus producing marked differences in lymph node irradiation.

Variations in the extent of leakage from the knee of the different colloids were small compared with the total amount retained, and of a similar order of magnitude to the measurement error. However, the amounts of radioactivity observed in the liver and lymph nodes were also of a similar order. It is therefore not surprising that factors which have little demonstrable effect on retention in the knee may still influence uptake in these other sites.

The retention of ${ }^{90} \mathrm{Y}$ ferric hydroxide colloid in the knee was as good as that reported for other ${ }^{90} \mathrm{Y}$ colloids. The retention at 5 days after injection, obtained from our observations by linear interpolation, was $87 \%$ compared with $78 \%$ (Gumpel and others, 1973) and $82 \%$ for ${ }^{90} \mathrm{Y}$ resin colloid, and $75 \%$ in the case of ${ }^{90} \mathrm{Y}$ citrate colloid (Gumpel and others, 1974). Comparison of these data is possible since similar methods of measurement were used. The retention in our study was significantly greater than only the first of these quoted values $(P<0.05)$, possibly because in that series the patients were not all strictly rested in bed.

We conclude that the use of ${ }^{90} \mathrm{Y}$ ferric hydroxide colloid is to be preferred to ${ }^{198} \mathrm{Au}$ colloid because of the possibly greater therapeutic effectiveness of the higher energy beta radiation (Ansell and others, 1963), the absence of the proportion of relatively high values of lymph node uptake which we found in some cases with ${ }^{198} \mathrm{Au}$, and the good retention in the knee. The results of a long-term clinical assessment of the different treatments will be reported separately. 
We are indebted to Dr. J. B. Gavin and Mrs. C. Smith, Pathology Department, Auckland University School of Medicine, for taking electron micrographs of the colloidal particles, and to Miss L. Gilmore, Department of Community Health, School of Medicine, for statistical advice. We thank the staff of the Department of Nuclear Medicine, Auckland Hospital, and Nursing Staff a Middlemore Hospital for their co-operation.

\section{References}

Ahlberg, A., Mikulowski, P., ANd Odelberg-Johnson, O. (1969) Acta. rheum. Scand., 15, 81 (Intraarticular injection of radioactive gold in the treatment of chronic synovial effusion in the knee)

Ansell, B. M., Crook, A., Mallard, J. R., and Bywaters, E. G. L. (1963) Ann. rheum. Dis., 22, 435 (Evaluation of intra-articular colloidal gold $\mathrm{Au}^{198}$ in the treatment of persistent knee effusions)

Caro, R. A., Nicolini, J. O., AND Radicella, R. (1968) Int. J. appl. Radiat., 19, 547 (Preparation and biological behaviour of radiogold colloids stabilized with polyvinylpyrrolidine)

FEARn, C. B. D'A. (1973) Ann. rheum. Dis., 32 (Suppl.), 34 (Studies of the spread of radioactive gold colloid)

Goode, J. D., AND HowEY, S. (1973) Ibid., 32 (Suppl.), 43 (Effect of premedication with intra-articular hydrocortison on the retention of ${ }^{198} \mathrm{Au}$ in the knee joint in rheumatoid arthritis)

Grahame, R., Ramsey, N. W., AND ScotT, J. T. (1970) Ibid., 29, 159 (Radioactive colloidal gold in chronic knee effusions with Baker's cyst formation)

Gumpel, J. M., AND Stevenson, A. C. (1975) Rheum. Rehab., 14, 7 (Chromosomal damage after intraarticular injection of different colloids of yttrium 90)

—, Williams, E. D., AND Glass, H. I. (1973) Ann. rheum. Dis., 32, 223 (Use of yttrium 90 in persistent synovitis of the knee. I. Retention in the knee and spread in the body after injection)

- FARRan, H. E. A., AND Williams, E. D. (1974) Ibid., 33, 126 (Use of yttrium 90 in persistent synovitis of the knee. II. Direct comparison of yttrium colloid resin and yttrium citrate)

Hurley, P. J. (1975) J. nucl. Med., 16, 46 (Red cell and plasma volumes in normal adults)

INGRAND, J. (1973) Ann. rheum. Dis., 32 (Suppl.), 3 (Characteristics of radioisotopes for intra-articular therapy)

Karjalainen, P., Kettunen, K., and Holopainen, T. (1972) Scand. J. Rheum., 1, 141 (Radio-technetium uptake in normal and diseased knee joints)

Oka, M., Rekonen, A., Ruotsi, A., AND Seppala, O. (1971) Acta. rheum. Scand., 17, 148 (Intra-articular injectiog of $\mathrm{Y}-90$ resin colloid in the treatment of rheumatoid knee joint effusions)

Prichard, H. L., Bridgman, J. F., AND Bleehen, N. M. (1970) Brit. J. Radiol., 43, 466 (An investigation of radioactive yttrium $\left({ }^{90} \mathrm{Y}\right)$ for the treatment of chronic knee effusions)

Ramsey, N. W. (1973) Ann. rheum Dis., 32 (Suppl.), 38 (Retention of ${ }^{90} Y$ in patients with rheumatoid arthritis)

Riccabona, G., AND Junger, H. (1970) Nucl.-Med. (Stuttg.), 9, 279 (Behandlung der rheumatischen Synovitis durch intraartikulare Gaben von $\left.{ }^{198} \mathrm{Au}-\mathrm{Kolloid}\right)$

Stevenson, A. C., Bedford, J., Dolphin, G. W., Purrott, R. J., Lloyd, D. C., Hill, A. G. S., Hill, H. F. H., Gumpel, J. M., Williams, D., Scott, J. T., Ramsey, N. W., Bruckner, F. E., ANd Fearn, C. B. D'A. (1973) Ann. rheum. Dis., 32, 112 (Cytogenetic and scanning study of patients receiving intra-articular injections of gold-198 and yttrium-90)

Topp, J. R., AND Cross, E. G. (1970) Canad. med. Ass. J., 102, 709 (The treatment of persistent knee effusions with intraarticular radioactive gold: preliminary report)

VirkKunen, M., Krusius, F.-E., AND Heiskanen, T. (1967) Acta. rheum. Scand., 13, 81 (Experiences of intraarticular administration of radioactive gold)

Williams, E. D. (1973a) Ann. rheum. Dis., 32 (Suppl.), 13 (Methods of measuring retention of radioisotopes in the knee and extra-articular spread in vivo)

- (1973b) In 'The measurement of localised radioactivity in the human body using a radioisotope scanner', p. 2000 Ph.D. thesis, University of London 